Fig. 3. Silicon solar cells manufaetured by Ferranti Limited at Oldham, Lancashire. The front face gold grids each consist of a $1 \mathrm{~mm}$ gold line along the top cdge of the cell with $0.2 \mathrm{~mm}$ gold current collector lines extend. ing to within $0.25 \mathrm{~mm}$ of the bottom edge. The reverse face gold area is surrounded by a 1 mm frame to prevent splashing during soldering

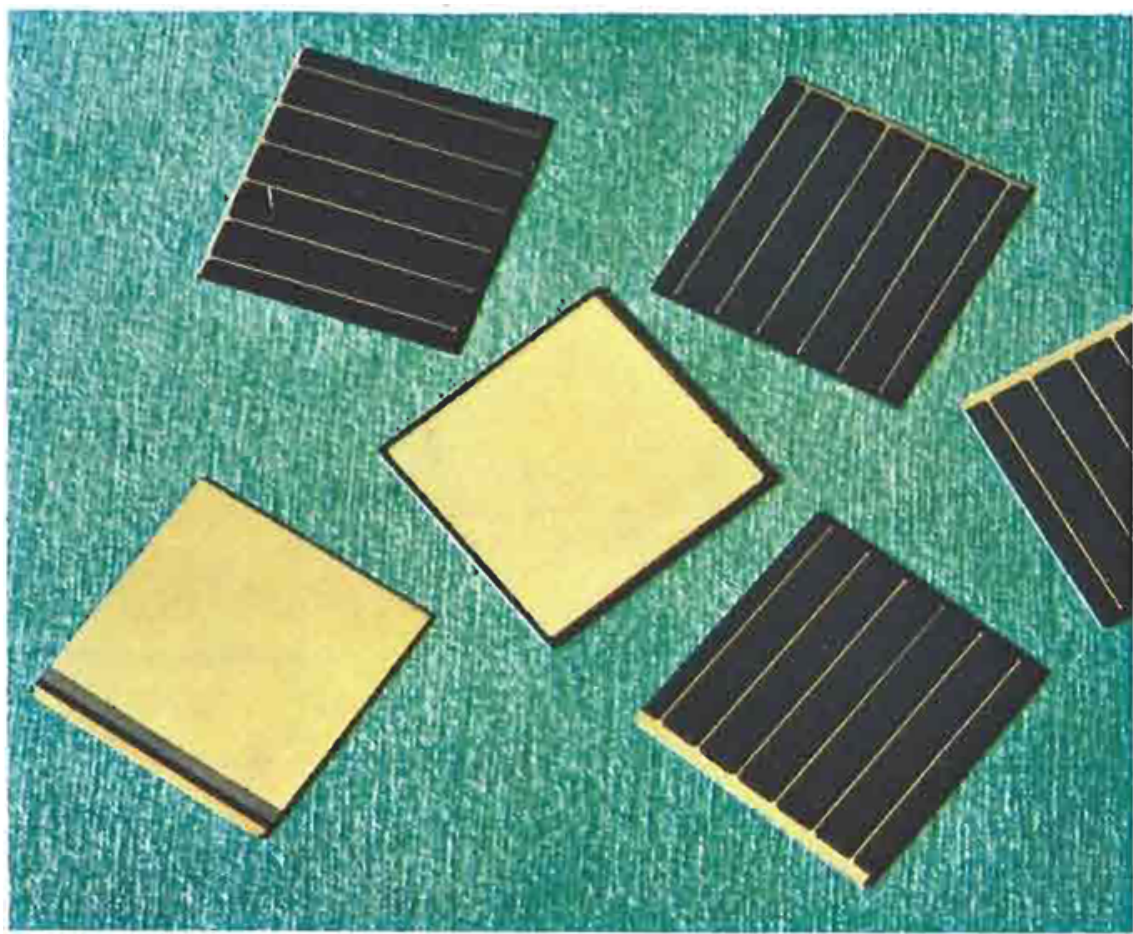

Each of the Ferranti silicon solar cells incorporates a contact structure, deposited electrochemically, of copper, nickel and gold on both its front and back faces as shown in Fig. 3. The front face of each cell receives the solar energy and to increase the efficiency of electron collection from this face a grid of fine gold lines is superimposed on the silicon. Gold is used because of its high electrical conductivity, together with its resistance to corrosion on earth during storage before flight. The gold grid consists of a $1 \mathrm{~mm}$ wide gold line along one edge of the $2 \mathrm{~cm}$ square cell. Six gold lines $0.2 \mathrm{~mm}$ wide extend from this line across the face of the cell to within $0.25 \mathrm{~mm}$ of the opposite edge. The gap prevents possible contact to the next cell below in the array.

Each cell is soldered into position in its array to make good electrical contact to the power circuit. The attachment is made to the large gold area on the back of the cell. Usually there is a $1 \mathrm{~mm}$ "picture frame" around the gold area to prevent splashing of solder during fabrication; such splashing might otherwise cause unwanted electrical connections to adjacent cells. Gold is used to assist solderability and it also inhibits oxidation of substrate copper during storage.

Ferranti has found that gold is superior to the materials used by other manufacturers for these two purposes. The same type of cell used in Intelsat IV has been supplied for the British experimental Prospero satellite. Cells for this vehicle have been assembled into panels for Marconi by Ernest Turner Electrical Instruments Ltd. Prospero (known as X3 before launch) was launched by the British Black Arrow rocket in October 1971. At the time of writing Ferranti have manufactured 140,000 of these cells for various types of satellite and are to supply cells for Britain's X4 satellite, the next in the series.

F. J. S.

\title{
A Proposed New High-pressure Calibration Scale
}

Geophysical research is currently being undertaken at pressure levels that must be estimated rather than measured and where the possibilities for error are very considerable. Practical measuring techniques are needed, therefore, which provide a pressure calibration curve that can be extrapolated with confidence from the lower accurately known levels up to pressures of the order of $200 \mathrm{kbar}$. The curve obtained by plotting the melting point of gold as a function of pressure can satisfy this requirement. It increases linearly from $1063^{\circ} \mathrm{C}$ at one atmosphere to $1404^{\circ} \mathrm{C}$ at
65 kbar and if extrapolated to 200 kbar a melting point of $1988^{\circ} \mathrm{C}$ would be expected. J. Akella and G. C. Kennedy of the University of California (7. Geophys. Res., 1971, 76, (20), 4969) have recently proposed that this curve should be used as a primary measuring standard between 100 and $200 \mathrm{kbar}$ and in the temperature interval 1600 to $2000^{\circ} \mathrm{C}$. Over this range, pressure differences of $0.5 \mathrm{kbar}$ correspond to temperature differences of 1 to $2 \mathrm{deg} C$, which should be measureable with a suitable high temperature thermocouple. 